\title{
Population pharmacokinetics/ pharmacodynamics of micafungin against Candida species in obese, critically ill, and morbidly obese critically ill patients
}

Emilio Maseda ${ }^{1,2^{*}+}$, Santiago Grau ${ }^{3,4 \dagger}$, Sonia Luque ${ }^{3,5}$, Maria-Pilar Castillo-Mafla ${ }^{1}$, Alejandro Suárez-de-la-Rica ${ }^{1}$, Ana Montero-Feijoo ${ }^{1}$, Patricia Salgado ${ }^{1}$, Maria-Jose Gimenez ${ }^{6}$, Carlos A. García-Bernedo ${ }^{7}$, Fernando Gilsanz ${ }^{1,2}$ and Jason A. Roberts $8,9,10,11$

\begin{abstract}
Background: Dosing in obese critically ill patients is challenging due to pathophysiological changes derived from obesity and/or critical illness, and it remains fully unexplored. This study estimated the micafungin probability of reaching adequate $24-\mathrm{h}$ area under the curve $\left(\mathrm{AUC}_{0-24 \mathrm{~h}}\right)$ /minimum inhibitory concentration (MIC) values against Candida spp. for an obese/nonobese, critically ill/noncritically ill, large population.

Methods: Blood samples for pharmacokinetic analyses were collected from 10 critically ill nonobese patients, 10 noncritically ill obese patients, and 11 critically ill morbidly obese patients under empirical/directed micafungin treatment. Patients received once daily 100-150 mg micafungin at the discretion of the treating physician following the prescribing information and hospital guidelines. Total micafungin concentrations were determined by highperformance liquid chromatography (HPLC). Monte-Carlo simulations were performed and the probability of target attainment (PTA) was calculated using the AUC $0-24 / \mathrm{MIC}$ cut-offs 285 (C. parapsilosis), 3000 (all Candida spp.), and 5000 (nonparapsilosis Candida spp.). Intravenous once-daily 100-mg, 150-mg, and 200-mg doses were simulated at different body weights $(45,80,115,150$, and $185 \mathrm{~kg})$ and age (30,50, 70 and 90 years old). PTAs $\geq 90 \%$ were considered optimal. Fractional target attainment (FTA) was calculated using published MIC distributions. A dosing regimen was considered successful if the FTA was $\geq 90 \%$.

Results: Overall, $100 \mathrm{mg}$ of micafungin was once-daily administered for nonobese and obese patients with body mass index (BMI) $\leq 45 \mathrm{~kg} / \mathrm{m}^{2}$ and $150 \mathrm{mg}$ for morbidly obese patients with $\mathrm{BMI}>45 \mathrm{~kg} / \mathrm{m}^{2}$ (except two noncritically ill obese patients with $\mathrm{BMl} \sim 35 \mathrm{~kg} / \mathrm{m}^{2}$ receiving $150 \mathrm{mg}$, and one critically ill patient with $\mathrm{BMl}>45 \mathrm{~kg} / \mathrm{m}^{2}$ receiving $100 \mathrm{mg}$ ). Micafungin concentrations in plasma were best described using a two-compartment model. Weight and age (but not severity score) were significant covariates and improved the model. FTAs $>90 \%$ were obtained against C. albicans with the $200 \mathrm{mg} / 24 \mathrm{~h}$ dose for all body weights (up to $185 \mathrm{~kg}$ ), and with the $150 \mathrm{mg} / 24 \mathrm{~h}$ for body weights $<115 \mathrm{~kg}$, and against C. glabrata with the $200 \mathrm{mg} / 24 \mathrm{~h}$ dose for body weights $<115 \mathrm{~kg}$.

(Continued on next page)
\end{abstract}

\footnotetext{
* Correspondence: emilio.maseda@gmail.com

tEqual contributors

${ }^{1}$ Department of Anesthesia and Surgical Intensive Care, Hospital Universitario

La Paz, Paseo de la Castellana 261, 28046 Madrid, Spain

${ }^{2}$ Universidad Autónoma de Madrid, Madrid, Spain

Full list of author information is available at the end of the article
} 
(Continued from previous page)

Conclusion: The lack of adequacy for the $100 \mathrm{mg} / 24 \mathrm{~h}$ dose suggested the need to increase the dose to $150 \mathrm{mg} / 24 \mathrm{~h}$ for C. albicans infections. Further pharmacokinetic/pharmacodynamic studies should address optimization of micafungin dosing for nonalbicans Candida infections.

Keywords: Morbid obesity, PK/PD, Monte-Carlo simulation, Intensive care unit, Candida spp.,

\section{Background}

Obesity, which is increasing at an alarming rate in developed countries, is a significant risk factor for nosocomial infections, especially following surgery due to the immune dysfunction associated with obesity [1]. In addition, pathophysiological changes in obese patients (e.g., reduced regional blood flow, altered cardiac output, increased fat and lean mass, etc.) might modify the pharmacokinetic/pharmacodynamic (PK/PD) profile of antimicrobials [2,3]. On the other hand, critically ill patients also present pathophysiological changes (hepatic and/or renal dysfunction, hypoalbuminemia or increased capillary permeability, use of organ support modalities) that can alter antimicrobial clearance and volume of distribution [4]. Thus, dosing in obese critically ill patients is a challenging scenario for intensivists that has not been fully explored [5].

Micafungin is an echinocandin, a lipopeptide that exhibits concentration-dependent fungicidal activity against most species of Candida [6], and is licensed as a first-line treatment for invasive candidiasis [7]. The recently published study EUROBACT was conducted in 162 intensive care units (ICUs) in 24 countries. It showed that, among patients with candidemia, Candida albicans was the most frequent fungi isolated (57.1\%), followed by Candida glabrata (15.3\%), Candida parapsilosis (10.2\%), and Candida tropicalis (6.1\%) [8].

Altered serum concentrations of micafungin associated with morbid obesity in critically ill patients might impact the achievement of therapeutic drug exposures as defined by the area under the serum concentration curve over a $24-\mathrm{h}$ period $\left(\mathrm{AUC}_{0-24 \mathrm{~h}}\right)$ / minimum inhibitory concentration (MIC), the pharmacodynamic index linked to clinical efficacy for micafungin $[9,10]$. A previous study conducted by our group showed cumulative fraction responses > $90 \%$ for micafungin at the standard dose $(100 \mathrm{mg})$ against C. albicans and C. glabrata in a special population of critically ill patients on continuous venovenous hemofiltration [11].

The aim of this study was to estimate the micafungin probability of achieving adequate $\mathrm{AUC}_{0-24 \mathrm{~h}} / \mathrm{MIC}$ values against Candida spp. for a large population using Monte-Carlo simulations [10] and data from obese, critically ill, and morbidly obese critically ill patients treated with micafungin.

\section{Methods}

A pharmacokinetic study was carried out in patients under micafungin empirical or directed treatment for invasive candidiasis. The population consisted of 11 morbidly obese critically ill adult patients (from the Hospital Universitario La Paz, Madrid, Spain), 10 nonobese critically ill patients, and 10 obese noncritically ill patients (from the Hospital del Mar, Barcelona, Spain). Patients admitted to ICUs were those considered to be critically ill. The study protocol was approved by the Ethics Committee of the Hospital La Paz (Madrid, Spain) and the Hospital del Mar (Barcelona, Spain). Written informed consent was obtained from patients (or relatives if the patient was unable to provide due to their critical situation) before blood sampling.

Demographic and clinical data prior to initiation of antifungal treatment were collected. Severity (Simplified Acute Physiology Score (SAPS) II) [12], Sequential Organ Failure Assessment (SOFA) score [13], and risk for invasive candidiasis (Candida score) [14] (except for patients with microbiologically documented infections) were calculated. Patients received dosage regimens of once-daily $100 \mathrm{mg}$ or $150 \mathrm{mg}$ micafungin (Astellas Pharma S.A., Spain) diluted in $100 \mathrm{ml}$ isotonic saline solution that was intravenously infused over $60 \mathrm{~min}$ at the discretion of the treating physician (following the prescribing information and hospital treatment guidelines). On day 3 , blood samples were collected at baseline (predose) and after 1, 3, 5, 8, 18, and $24 \mathrm{~h}$. Additional blood samples at day 0 and day 7 were collected when feasible.

\section{Sample handling and storage}

Blood samples were immediately placed on ice and centrifuged at $3000 \mathrm{rpm}$ for $10 \mathrm{~min}$. Following on, they were stored at $-80{ }^{\circ} \mathrm{C}$. The samples were transported by a commercial courier company to the Burns Trauma and Critical Care Research Centre, The University of Queensland, Australia, for further analysis. 


\section{Drug assay}

Total micafungin concentrations in plasma were measured by a validated ultra-high-performance liquid chromatography (UHPLC)-tandem mass spectrometry (MS/ MS) method, from 0.2 to $30 \mu \mathrm{g} / \mathrm{ml}$, on a Shimadzu Nexera 2 UHPLC system coupled to a Shimadzu 8030+ triple quadruple mass spectrometer (Shimadzu, Kyoto, Japan) [15]. Clinical samples were assayed alongside plasma calibrators and quality controls and met batch acceptance criteria [16].

\section{Generation of large population data Population pharmacokinetic modeling}

To describe total micafungin concentrations, one- and two-compartment models were developed with the nonparametric adaptive grid algorithm within the freely available Pmetrics software package for R (Los Angeles, CA, USA) $[17,18]$. Elimination from the central compartment, and intercompartmental distribution into the peripheral compartment (two-compartment model), were modeled as first-order processes. The discrimination between different models resulted from the comparison of the -2 log-likelihood (-2LL). A $p$ value of $<0.05$ was considered statistically significant.

\section{Population pharmacokinetics covariate screening}

Age, gender, body weight, body mass index (BMI), Acute Physiology and Chronic Health Evaluation (APACHE) II, serum creatinine concentration, measured creatinine clearance, Cockroft-Gault estimated creatinine clearance, and serum albumin concentration were evaluated as covariates. Covariate selection was performed using a stepwise linear regression from $\mathrm{R}$ on all covariates and Bayesian posterior parameters. Potential covariates were separately entered into the model and statistically tested by use of the $-2 \mathrm{LL}$ values. If inclusion of the covariate resulted in a statistically significant improvement in the LL values $(p<0.05)$ and in an improvement of the goodness-of-fit plots, then the covariate was retained in the final model.

\section{Model diagnostics}

Goodness-of-fit was assessed by linear regression, with an observed-predicted plot, coefficients of determination, and LL values. Predictive performance evaluation was based on mean error of prediction (bias) and mean bias-adjusted squared error of prediction (imprecision) of the population and individual prediction models. The internal validity of the population pharmacokinetic model was assessed by the bootstrap resampling method $(n=1000)$ and normalized prediction distribution errors (NPDE) [19]. Using a visual predictive check method, parameters obtained from the bootstrap method were plotted with the observed concentrations. NPDE plots were checked for normal distribution characteristics and trends in data errors [19].

\section{Probability of target attainment (PTA)}

Monte-Carlo simulations $(n=1000)$ were employed using Pmetrics software to determine the PTA of achieving the $\mathrm{PK} / \mathrm{PD}$ target of $\mathrm{AUC}_{0-24} / \mathrm{MIC}$ (285 for C. parapsilosis, 3000 for all Candida spp., and 5000 for nonparapsilosis Candida spp.) [11] for varying MICs (0.008 to $1 \mu \mathrm{g} / \mathrm{ml})$. Intravenous once-daily doses of $100 \mathrm{mg}, 150 \mathrm{mg}$, and $200 \mathrm{mg}$ were simulated at different body weight (45, 80, $115,150$, and $185 \mathrm{~kg})$ and age $(30,50,70$, and 90 years old). PTAs $\geq 90 \%$ were considered optimal.

\section{Fractional target attainment (FTA) calculation}

Published MIC distribution data of C. parapsilosis, nonparapsilosis Candida spp., and all Candida spp. from the SENTRY study [20] were used to determine the FTA, which identifies the potential success of the treatment by comparing the pharmacodynamic exposure (i.e, PTA) against an MIC distribution. Specifically, PTA values determined at each MIC were multiplied by the fraction of isolates found at that MIC, and the sum of the products equaled the FTA. A value of FTA $\geq 90 \%$ against a population of organisms was considered optimal.

\section{Statistical analysis}

Correlations were assessed by means of scatter graphs and the Pearson correlation coefficient $(r)$.

\section{Results}

Table 1 shows the demographic data, baseline analytical parameters, and clinical scores for the patients distributed by obese/nonobese and critically/noncritically ill categorization. Overall, the standard 100-mg dose of micafungin was once-daily administered for nonobese and obese patients with BMI $\leq 45 \mathrm{~kg} / \mathrm{m}^{2}$. The $150-\mathrm{mg}$ dose was administered for morbidly obese patients with BMI $>45 \mathrm{~kg} / \mathrm{m}^{2}$, with the exception of two noncritically ill obese patients with BMI of around $35 \mathrm{~kg} / \mathrm{m}^{2}$ who received the $150-\mathrm{mg}$ dose, and one critically ill patient with $\mathrm{BMI}>45 \mathrm{~kg} / \mathrm{m}^{2}$ who received the 100-mg dose.

Figure 1 shows the mean observed concentration-time profile of micafungin concentrations for the study population.

\section{Pharmacokinetic model}

A two-compartment linear model (including zero order input of drug into the central compartment) best described the time course of 242 total plasma concentrations of micafungin. The goodness-of-fit of the model was improved $(p<0.05)$ by the inclusion of the covariate body weight (normalized to $70 \mathrm{~kg}$ ) and age (normalized to 60 years old to an exponential value of 0.75 ) for micafungin clearance. 
Table 1 Demographic and clinical data

\begin{tabular}{|c|c|c|c|c|c|c|}
\hline \multirow{2}{*}{$\frac{\text { Variable }}{\text { Dose (mg) }}$} & \multirow[t]{2}{*}{ Total } & \multicolumn{2}{|c|}{ Critically morbidly obese } & \multicolumn{2}{|c|}{ Noncritically obese } & \multirow{2}{*}{$\frac{\text { Critically nonobese }}{100}$} \\
\hline & & 100 & 150 & 100 & 150 & \\
\hline$n$ & 31 & 7 & 4 & 7 & 3 & 10 \\
\hline Age (years), median (range) & $58(27-85)$ & $45(27-73)$ & $53.5(44-63)$ & $58(48-85)$ & $58(43-73)$ & $72(43-85)$ \\
\hline$\%$ Females & 71.0 & 100 & 50.0 & 85.7 & 100 & 40 \\
\hline $\mathrm{BMI}^{\mathrm{a}}\left(\mathrm{kg} / \mathrm{m}^{2}\right)$, median (range) & $34.7(19.6-60.0)$ & $44.2(40.3-51.7)$ & $52.8(47.4-60.0)$ & $27.7(25.2-34.7)$ & $35.5(34.7-52.4)$ & $23.1(19.6-38.5)$ \\
\hline Weight (kg), median (range) & $95(44-193)$ & $113(95-121)$ & $157.5(142-170)$ & $84.1(62-105)$ & $105(105-193)$ & $65(44.0-92.5)$ \\
\hline Creatinine (mg/dl), median (range) & $1.0(0.4-3.9)$ & $0.7(0.6-1.5)$ & $1.3(0.6-1.7)$ & $1.1(0.7-1.4)$ & $0.8(0.7-1.5)$ & $1.0(0.4-3.0)$ \\
\hline $\mathrm{CrCl}^{\mathrm{a}}\left(\mathrm{ml} / \mathrm{min} / 1.73 \mathrm{~m}^{2}\right)$ & $93.4 \pm 51.4$ & $133.1 \pm 44.9$ & $112.5 \pm 53.2$ & $62.7 \pm 38.4$ & $105.4 \pm 63.9$ & $75.9 \pm 46.1$ \\
\hline Albumin (g/dl), median (range) & $3(1.2-4.0)$ & $2.7(1.9-3.5)$ & $3.1(2.4-4)$ & $3.5(2.6-3.9)$ & $3.6(3.4-3.7)$ & $2.5(1.2-3.3)$ \\
\hline Candida score, median (range) & $3(2-4)^{b}$ & $3(2-4)$ & $3.5(3-4)$ & $\mathrm{DT}^{\mathrm{c}}$ & $D T^{d}$ & $3(2-4)$ \\
\hline SOFA ${ }^{a}$ score, median (range) & $6(0-12)$ & $6(2-8)$ & $7(5-10)$ & $5(2-10)$ & $6(5-7)$ & $4.5(0-12)$ \\
\hline SAPS ${ }^{a}$ II, median (range) & $34(9-57)$ & $40(8-57)$ & $34.5(25-45)$ & $47(9-53)$ & $41(18-44)$ & $26(11-42)$ \\
\hline
\end{tabular}

Data are expressed as mean \pm standard deviation, except where stated

${ }^{a} B M I$, Body mass index; $\mathrm{CrCl}$, creatinine clearance; SAPS, Simplified Acute Physiology Score; SOFA, Sequential Organ Failure Assessment

${ }^{b}$ For 21 patients

c Directed treatment (DT): three candidemia, three osteoarticular infections, and one urinary tract infection

${ }^{d}$ DT: one peritonitis, one urinary tract infection, and one osteoarticular infection

Use of this exponent on age improved the model better than either covariate added as a linear function alone and reflected the likely nonlinear effect of the increasing body weight and age on micafungin clearance. Addition of body weight or age alone did not statistically improve the model when compared with the structural model $(-2 \mathrm{LL}$ value, 595.2 vs 596.4 for weight inclusion, $p=0.0586$; 587.5 vs 596.4 for age inclusion, $p=0.597$ ). When both the covariates body weight and age were included, the log likelihood value decreased significantly $(-2 \mathrm{LL}, 415.6 ; p=0.0238)$ and the goodness-of-fit of the model also showed an improvement. The final covariate model was as follows:

$$
\text { Micafungin } \mathrm{CL}=\mathrm{TVCL}_{*}(\mathrm{Wt} / 70)^{0.75}(\text { Age } / 60)^{0.75}
$$

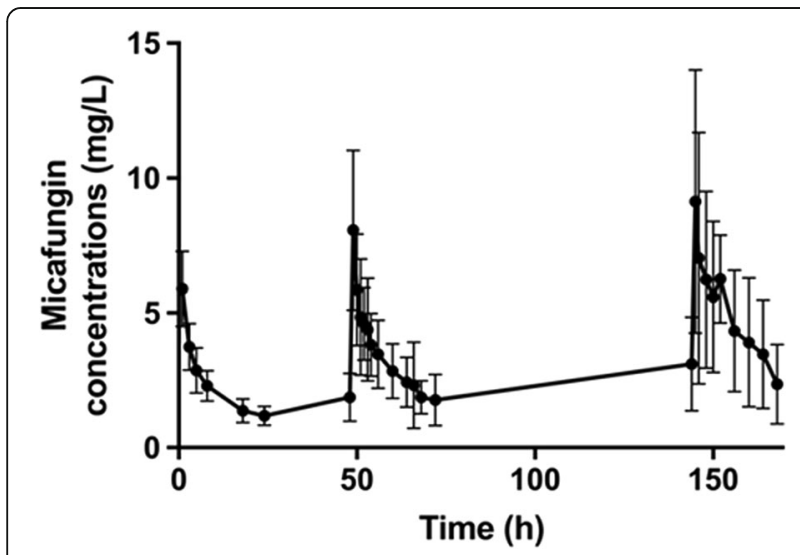

Fig. 1 Micafungin concentrations. Mean observed micafungin concentration-time profiles (error bars represent standard deviation)
Where TVCL is the typical value of micafungin clearance, Wt is the total body weight $(\mathrm{kg})$ and Age is the patient's age (years).

The mean \pm standard deviation (SD) population pharmacokinetic parameter estimates for the final covariate model are shown in Table 2. The diagnostic plots confirmed the appropriateness of the model as shown in Fig. 2. The final covariate model was then used for Monte-Carlo dosing simulations.

\section{Dosing simulations}

PTAs for $\mathrm{AUC}_{0-24} / \mathrm{MIC}$ of 285,3000 , or 5000 for different micafungin doses (100 mg, $150 \mathrm{mg}, 200 \mathrm{mg}$ ) and body weights (from $45 \mathrm{~kg}$ to $185 \mathrm{~kg}$ ) for patients with a medium age of 70 years old (no significant changes were observed in simulations with different patient ages) are described in Table 3. The MonteCarlo simulations showed that increases in the micafungin dose resulted in increased PTAs. For nonparapsilosis Candida (AUC/MIC > 5000) this

Table 2 Estimated micafungin parameters

\begin{tabular}{lllll}
\hline Parameters & Mean \pm SD & $\begin{array}{l}\text { Coefficient of } \\
\text { variation (\%) }\end{array}$ & Variance & Median \\
\hline Clearance $(\mathrm{I} / \mathrm{h})$ & $0.80 \pm 0.49$ & 61.78 & 0.24 & 0.73 \\
Central volume (I) & $16.34 \pm 5.87$ & 35.95 & 34.49 & 16.34 \\
$\mathrm{kcp}\left(\mathrm{h}^{-1}\right)$ & $0.38 \pm 0.37$ & 97.76 & 0.14 & 0.26 \\
$\mathrm{kpc}\left(\mathrm{h}^{-1}\right)$ & $0.32 \pm 0.31$ & 96.51 & 0.09 & 0.14 \\
\hline
\end{tabular}

Parameter estimates for micafungin from the final two-compartment covariate population pharmacokinetic model

$k c p$, rate constant for drug distribution from the central to peripheral compartment; $\mathrm{kpc}$, rate constant for drug distribution from the peripheral to central compartment 

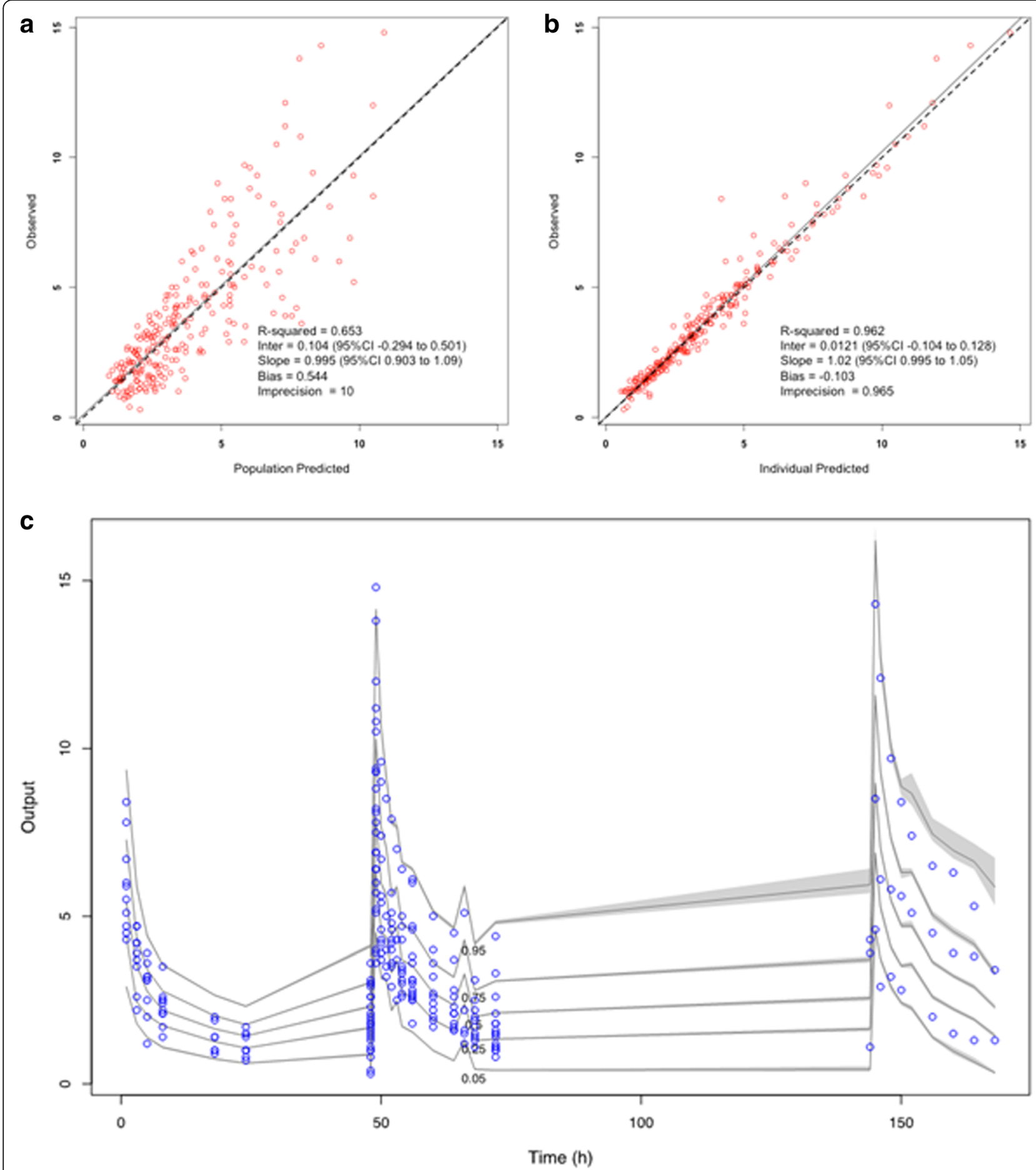

Fig. 2 Diagnostic plots for the final population pharmacokinetic covariate model. a Observed micafungin concentrations versus population predicted concentrations. b Observed micafungin concentrations versus individual predicted concentrations. c Visual predictive check (circles represent observed data). Concentrations are expressed as $\mu \mathrm{g} / \mathrm{ml}$

target attainment was only obtained with >90\% probability with doses of $150 \mathrm{mg}$ and $200 \mathrm{mg}$ against isolates with MICs up to $0.008 \mu \mathrm{g} / \mathrm{ml}$, regardless of the patient's weight.
FTAs for the simulated PTAs against MIC distributions for C. albicans, C. glabrata, C. parapsilosis, and C. tropicalis are shown in Table 4. FTAs $>90 \%$ were obtained against $C$. albicans with the $200 \mathrm{mg} / 24 \mathrm{~h}$ dose for all body weights, 
Table 3 Probability of target attainment (PTA) for micafungin

\begin{tabular}{|c|c|c|c|c|c|c|c|c|c|c|c|c|c|c|c|c|}
\hline \multirow[b]{2}{*}{ Dose (mg/24 h) } & \multirow[b]{2}{*}{ MIC $(\mu \mathrm{g} / \mathrm{ml})$} & \multicolumn{5}{|c|}{$\begin{array}{l}\mathrm{AUC}_{0-24} / \mathrm{MIC} \text { of } 285 \text { for } \\
\text { body weight }(\mathrm{kg}) \text { equal to: }\end{array}$} & \multicolumn{5}{|c|}{$\begin{array}{l}\mathrm{AUC}_{0-24} / \mathrm{MIC} \text { of } 3000 \text { for } \\
\text { body weight (kg) equal to: }\end{array}$} & \multicolumn{5}{|c|}{$\begin{array}{l}\mathrm{AUC}_{0-24} / \mathrm{MIC} \text { of } 5000 \text { for } \\
\text { body weight (kg) equal to: }\end{array}$} \\
\hline & & 45 & 80 & 115 & 150 & 185 & 45 & 80 & 115 & 150 & 185 & 45 & 80 & 115 & 150 & 185 \\
\hline \multirow[t]{8}{*}{100} & 0.008 & 100 & 100 & 100 & 100 & 100 & 99.0 & 98.9 & 98.8 & 98.5 & 97.8 & 83.7 & 78.4 & 72.3 & 64.0 & 55.1 \\
\hline & 0.016 & 100 & 100 & 100 & 100 & 100 & 72.0 & 58.8 & 52.2 & 40.9 & 31.1 & 9.2 & 3.7 & 1.4 & 0.5 & 0.2 \\
\hline & 0.032 & 100 & 100 & 100 & 100 & 100 & 23.0 & 0.7 & 0.1 & 0.1 & 0.0 & 0.0 & 0.0 & 0.0 & 0.0 & 0.0 \\
\hline & 0.064 & 99.9 & 99.7 & 99.7 & 99.7 & 99.6 & 0.0 & 0.0 & 0.0 & 0.0 & 0.0 & 0.0 & 0.0 & 0.0 & 0.0 & 0.0 \\
\hline & 0.125 & 93.8 & 85.6 & 79.0 & 75.8 & 71.2 & 0.0 & 0.0 & 0.0 & 0.0 & 0.0 & 0.0 & 0.0 & 0.0 & 0.0 & 0.0 \\
\hline & 0.25 & 23.4 & 9.8 & 4.8 & 1.9 & 0.8 & 0.0 & 0.0 & 0.0 & 0.0 & 0.0 & 0.0 & 0.0 & 0.0 & 0.0 & 0.0 \\
\hline & 0.5 & 0.0 & 0.0 & 0.0 & 0.0 & 0.0 & 0.0 & 0.0 & 0.0 & 0.0 & 0.0 & 0.0 & 0.0 & 0.0 & 0.0 & 0.0 \\
\hline & 1 & 0.0 & 0.0 & 0.0 & 0.0 & 0.0 & 0.0 & 0.0 & 0.0 & 0.0 & 0.0 & 0.0 & 0.0 & 0.0 & 0.0 & 0.0 \\
\hline \multirow[t]{8}{*}{150} & 0.008 & 100 & 100 & 100 & 100 & 100 & 100 & 100 & 100 & 99.9 & 99.8 & 98.8 & 98.4 & 98.1 & 97.2 & 91.3 \\
\hline & 0.016 & 100 & 100 & 100 & 100 & 100 & 96.7 & 95.5 & 89.6 & 80.8 & 78.6 & 57.3 & 49.2 & 35.4 & 25.3 & 17.6 \\
\hline & 0.032 & 100 & 100 & 100 & 100 & 100 & 38.5 & 22.2 & 12.3 & 6.9 & 3.0 & 0.9 & 0.1 & 0.1 & 0.0 & 0.0 \\
\hline & 0.064 & 100 & 100 & 100 & 100 & 100 & 0.1 & 0.0 & 0.0 & 0.0 & 0.0 & 0.0 & 0.0 & 0.0 & 0.0 & 0.0 \\
\hline & 0.125 & 99.1 & 98.9 & 98.9 & 98.6 & 98.0 & 0.0 & 0.0 & 0.0 & 0.0 & 0.0 & 0.0 & 0.0 & 0.0 & 0.0 & 0.0 \\
\hline & 0.25 & 72.8 & 59.8 & 52.8 & 42.7 & 32.5 & 0.0 & 0.0 & 0.0 & 0.0 & 0.0 & 0.0 & 0.0 & 0.0 & 0.0 & 0.0 \\
\hline & 0.5 & 2.5 & 0.8 & 0.1 & 0.1 & 0.0 & 0.0 & 0.0 & 0.0 & 0.0 & 0.0 & 0.0 & 0.0 & 0.0 & 0.0 & 0.0 \\
\hline & 1 & 0.0 & 0.0 & 0.0 & 0.0 & 0.0 & 0.0 & 0.0 & 0.0 & 0.0 & 0.0 & 0.0 & 0.0 & 0.0 & 0.0 & 0.0 \\
\hline \multirow[t]{8}{*}{200} & 0.008 & 100 & 100 & 100 & 100 & 100 & 100 & 100 & 100 & 100 & 100 & 99.7 & 99.7 & 99.6 & 99.4 & 99.1 \\
\hline & 0.016 & 100 & 100 & 100 & 100 & 100 & 99.0 & 98.9 & 98.8 & 98.5 & 97.8 & 83.7 & 78.4 & 72.3 & 64.0 & 55.1 \\
\hline & 0.032 & 100 & 100 & 100 & 100 & 100 & 72.0 & 58.8 & 52.2 & 40.9 & 31.1 & 9.2 & 3.7 & 1.4 & 0.5 & 0.2 \\
\hline & 0.064 & 100 & 100 & 100 & 100 & 100 & 2.3 & 0.7 & 0.1 & 0.1 & 0.0 & 0.0 & 0.0 & 0.0 & 0.0 & 0.0 \\
\hline & 0.125 & 99.9 & 99.8 & 99.7 & 99.7 & 99.7 & 0.0 & 0.0 & 0.0 & 0.0 & 0.0 & 0.0 & 0.0 & 0.0 & 0.0 & 0.0 \\
\hline & 0.25 & 93.8 & 85.6 & 79.0 & 75.8 & 71.2 & 0.0 & 0.0 & 0.0 & 0.0 & 0.0 & 0.0 & 0.0 & 0.0 & 0.0 & 0.0 \\
\hline & 0.5 & 23.4 & 9.8 & 4.8 & 1.9 & 0.8 & 0.0 & 0.0 & 0.0 & 0.0 & 0.0 & 0.0 & 0.0 & 0.0 & 0.0 & 0.0 \\
\hline & 1 & 0.0 & 0.0 & 0.0 & 0.0 & 0.0 & 0.0 & 0.0 & 0.0 & 0.0 & 0.0 & 0.0 & 0.0 & 0.0 & 0.0 & 0.0 \\
\hline
\end{tabular}

Micafungin PTA for different target values of area under the serum concentration curve over a 24-h period divided by the minimum inhibitory concentration $\left(\mathrm{AUC}_{0-24} / \mathrm{MIC}\right)$, body weights, and once-daily doses

and with the $150 \mathrm{mg} / 24 \mathrm{~h}$ dose for body weights of $45 \mathrm{~kg}$, $80 \mathrm{~kg}$, and $115 \mathrm{~kg}$, and against C. glabrata for body weights of $45 \mathrm{~kg}, 80 \mathrm{~kg}$, and $115 \mathrm{~kg}$ with the $200 \mathrm{mg} / 24 \mathrm{~h}$ dose. No FTAs $>90 \%$ were obtained with the $100 \mathrm{mg} / 24 \mathrm{~h}$ dose regardless of the species or the patient's weight.

\section{Discussion}

The present Monte-Carlo simulation using data from obese, critically ill, and morbidly obese critically ill patients treated with micafungin estimated the micafungin probability of achieving adequate $\mathrm{AUC}_{0-24 \mathrm{~h}} / \mathrm{MIC}$ values against Candida spp. for a large population. Our results showed the lack of adequate micafungin exposure (in terms of FTAs) with the $100 \mathrm{mg} / 24 \mathrm{~h}$ dose regardless of the Candida species or the patient's weight. Against C. albicans, micafungin exposure was adequate with the $150 \mathrm{mg} /$ $24 \mathrm{~h}$ dose for patients weighing up to $115 \mathrm{~kg}$ and with the $200 \mathrm{mg} / 24 \mathrm{~h}$ dose for those surpassing such a weight.

Table 4 Fractional target attainment (FTA) for micafungin

\begin{tabular}{|c|c|c|c|c|c|c|c|c|c|c|c|c|c|c|c|}
\hline \multirow[b]{2}{*}{ Body weight $(\mathrm{kg})$} & \multicolumn{5}{|c|}{$100 \mathrm{mg} / 24 \mathrm{~h}$} & \multicolumn{5}{|c|}{$150 \mathrm{mg} / 24 \mathrm{~h}$} & \multicolumn{5}{|c|}{$200 \mathrm{mg} / 24 \mathrm{~h}$} \\
\hline & 45 & 80 & 115 & 150 & 185 & 45 & 80 & 115 & 150 & 185 & 45 & 80 & 115 & 150 & 185 \\
\hline C. albicans & 74.6 & 62.6 & 56.6 & 46.4 & 37.4 & 97.0 & 95.9 & 90.6 & 82.6 & 80.6 & 99.1 & 99.0 & 98.9 & 98.6 & 98.0 \\
\hline C. glabrata & 62.0 & 52.3 & 47.5 & 39.3 & 32.2 & 86.4 & 82.6 & 76.5 & 69.3 & 67.0 & 94.2 & 91.7 & 90.4 & 88.1 & 85.8 \\
\hline C. tropicalis & 23.9 & 19.3 & 17.1 & 15.9 & 11.0 & 49.6 & 40.8 & 34.1 & 28.8 & 26.1 & 67.9 & 60.8 & 57.3 & 51.4 & 46.1 \\
\hline C. parapsilosis & 1.6 & 1.2 & 1.0 & 0.9 & 0.9 & 3.6 & 2.7 & 2.4 & 2.2 & 1.9 & 6.6 & 4.6 & 3.7 & 3.3 & 3.0 \\
\hline
\end{tabular}


As in previous studies, plasma concentrations of micafungin were best described using a two-compartment model and, as mentioned, weight was a significant covariate [21]. Unlike the introduction of the severity score as a covariate, introducing the patient's age improved the model. The influence of severity scores on micafungin exposure in severely ill patients is controversial among studies in the literature; while one study considered SOFA as a relevant covariate [22], another study did not find a correlation of APACHE II or SOFA with exposure, suggesting the possibility of being ruled out as a cause of low drug exposure [23]. The reason for this could be the high interindividual variability found in studies investigating micafungin exposure in critically ill patients [23-25] in contrast to data from healthy volunteers or patients under continuous venovenous hemofiltration $[11,24]$, which represent more uniform populations.

On the contrary, weight has been described as markedly influencing micafungin clearance [21] both in patients weighing $>66.3 \mathrm{~kg} \mathrm{[26]} \mathrm{and} \mathrm{in} \mathrm{healthy} \mathrm{volunteers} \mathrm{in} \mathrm{a} \mathrm{study}$ including subjects with BMI $<25,25-40$, and $>40 \mathrm{~kg} / \mathrm{m}^{2}$ $[27,28]$. In the present simulation, the inclusion of weight as a covariate improved the model. According to the results of our model, for MIC values $>0.008 \mu \mathrm{g} / \mathrm{ml}$, the $100 \mathrm{mg} / 24$ $\mathrm{h}$ dose failed to achieve the optimal ratio threshold of $\mathrm{AUC}_{0-24 \mathrm{~h}} / \mathrm{MIC}$ of 3000 . This cut-off was associated with therapeutic outcome in animal models for disseminated candidiasis by C. albicans [29], and it was extrapolated to humans [9] using data from clinical trials of invasive candidiasis/candidemia [30]. The increase in micafungin exposure provided by the doses of 150 or $200 \mathrm{mg} / 24 \mathrm{~h}$ markedly improved the coverage encompassing MICs of 0 . $016 \mu \mathrm{g} / \mathrm{ml}$ for body weights up to $80 \mathrm{~kg}$ (with the $150 \mathrm{mg} /$ $24 \mathrm{~h}$ dose) or for all body weights (200 $\mathrm{mg} / 24 \mathrm{~h}$ dose). When considering recent MIC distributions for C. albicans, the most frequent isolated species, our results indicate that, to obtain adequate coverage ( $\mathrm{FTA} \geq 90 \%$ ), the micafungin dose should be increased to $150 \mathrm{mg} / 24 \mathrm{~h}$ for nonobese patients $(\leq 115 \mathrm{~kg})$ and to $200 \mathrm{mg} / 24-\mathrm{h}$ for those with body weight $>115 \mathrm{~kg}$. This finding is consistent with previous reports showing the need for an increase in doses of antifungals in obese patients $[5,15,31,32]$ due to inadequate exposure with standards doses, as described with micafungin $[26,33]$. In this sense, there is a report suggesting inadequate exposure with micafungin $100 \mathrm{mg} / 24 \mathrm{~h}$ in an obese critically ill patient weighing $230 \mathrm{~kg}$ [34]. Exposure may be crucial in morbidly obese critically ill patients when compared with the ICU population or obesity alone [32]. A timely and sufficiently high exposure to the appropriate antifungal agent is essential for the eradication of the pathogen. This acquires importance since, worldwide, mean weight, both in men and women, has been increasing over the last decades. In the USA, during 2013 and 2014, the overall age-adjusted prevalence of obesity was $37.7 \%$ [35].
Increasing the dose to $200 \mathrm{mg} / 24 \mathrm{~h}$ would overcome the problem caused by being overweight for C. albicans; however, such an increase would not solve the problem for other Candida species, requiring higher exposures. Since a previous study indicated that the maximum tolerated dose of micafungin in patients undergoing hematopoietic stem cell transplantation was at least up to $8 \mathrm{mg} / \mathrm{kg} / 24 \mathrm{~h}$ [36], strategies including individualized dosing have been advocated as a great opportunity to further improve the efficacy of micafungin [27], an antifungal with reported $70-80 \%$ efficacy in the treatment of candidemia with the current dosing of $100 \mathrm{mg} / 24 \mathrm{~h}[27,30,37,38]$.

The results of this study are of high importance due to the very limited information available on the pharmacokinetics and efficacy of echinocandins in obese critically ill patients, especially in those with morbid obesity. Most studies have been performed with caspofungin. In agreement with our results, pharmacokinetic studies with caspofungin showed lower exposure in overweight and obese patients, whether critically ill [39] or not [40], and also showed the benefits of increasing the dose in morbidly obese patients [41]. Similarly, the limited data in the literature regarding the influence of obesity on the pharmacokinetics of anidulafungin confirm the lower anidulafungin exposure in patients with morbid obesity compared with nonobese patients [32] and the need for increasing the dose in a critically ill morbid obese patient [42].

The present study is the first population assessment of micafungin in critically ill nonobese, noncritically ill obese, and critically ill morbidly obese patients. Several limitations and challenges must be kept in mind in this respect. Despite the relatively large sample size in this study, the distribution of patients resulted in a low number of individuals in some of the groups. In addition, the present study is a pharmacodynamic modeling not designed to examine the effect of micafungin exposure on patient outcome; clinical trials should address this issue from a clinical perspective.

\section{Conclusion}

The results of this study indicate that micafungin exposure was adequate with the $150 \mathrm{mg} / 24 \mathrm{~h}$ dose for patients weighing up to $115 \mathrm{~kg}$ and with the $200 \mathrm{mg} / 24 \mathrm{~h}$ dose for those surpassing such weight to cover $C$. albicans. The $200 \mathrm{mg} / 24$ h dose covered C. glabrata for patients weighing up to $115 \mathrm{~kg}$. Since other species of Candida were not successfully covered, further PK/PD studies should address this point to optimize dosing for nonalbicans Candida infections.

\section{Abbreviations}

APACHE: Acute Physiology and Chronic Health Evaluation; AUC: Area under the curve; BMI: Body mass index; FTA: Fractional target attainment;

ICU: Intensive care unit; LL: Log-likelihood; MIC: Minimum inhibitory 
concentration; MS/MS: Tandem mass spectrometry; NPDE: Normalized prediction distribution errors; PK/PD: Pharmacokinetic/pharmacodynamic; PTA: Probability of target attainment; SAPS: Simplified Acute Physiology Score; SD: Standard deviation; SOFA: Sequential Organ Failure Assessment; UHPLC: Ultra-high-performance liquid chromatography

\section{Acknowledgements}

The authors thank A. López-Tofiño and C. Hernández Gancedo (Department of Anesthesia and Surgical Intensive Care, Hospital Universitario La Paz, Madrid, Spain) for their support during the study, and L. Aguilar (PRISM-AG) for his critical review of the manuscript.

\section{Funding}

This work was supported in part by an unrestricted grant from Astellas Pharma S.A. (Madrid, Spain). The funder had no role in the study design, data collection and interpretation, or the decision to submit the work for publication. JAR is funded by a Career Development Fellowship from the National Health and Medical Research Council of Australia (APP1048652).

\section{Availability of data and materials}

Data from patients are recorded in their corresponding medical records at participating hospitals. The anonymous datasets used and/or analyzed during the current study are available from the corresponding author on reasonable request and with permission of the corresponding hospital.

\section{Authors' contributions}

EM, SG, and JAR designed the study. EM, M-PC-M, AS-d-I-R, AM-F, CAG-B, and FG collected data. SG, SL, and JAR analyzed blood samples and analyzed data. EM, SG, JAR, and M-JG analyzed results and prepared the manuscript. All authors read and approved the final manuscript.

\section{Ethics approval and consent to participate}

The study protocol was approved by the Ethics Committee of Hospital La Paz (Madrid, Spain) and Hospital del Mar (Barcelona, Spain). Written informed consent was obtained from patients (or relatives if the patient was unable to provide due to their critical situation) before blood sampling.

\section{Competing interests}

EM has received consultancy fees and payment for lectures from Astellas Pharma S.A. (Madrid, Spain), Pfizer, Novartis, Angellini, and Merck Sharp and Dohme. SG has received grants for research from Astellas Pharma S.A. (Madrid, Spain), Pfizer, Roche Pharma, and Angelini Pharma, and funds for speaking at symposia organized by Pfizer, Astellas Pharma S.A., and Merck Sharp and Dohme. SL has received travel grants from Astellas Pharma for medical conference attendance. CAG-B has received travel grants from Astellas Pharma for Sepsis Valladolid 2014 Congress attendance. The remaining authors declare that they have no competing interests.

\section{Publisher's Note}

Springer Nature remains neutral with regard to jurisdictional claims in published maps and institutional affiliations.

\footnotetext{
Author details

${ }^{1}$ Department of Anesthesia and Surgical Intensive Care, Hospital Universitario La Paz, Paseo de la Castellana 261, 28046 Madrid, Spain. ${ }^{2}$ Universidad Autónoma de Madrid, Madrid, Spain. ${ }^{3}$ Pharmacy Department, Hospital del Mar, Barcelona, Spain. ${ }^{4}$ Institut Hospital del Mar d'Investigacions Mèdiques (IMIM), Barcelona, Spain. ${ }^{5}$ Universitat Autónoma de Barcelona, Barcelona, Spain. ${ }^{6}$ PRISM-AG, Madrid, Spain. ${ }^{7}$ Anesthesiology Department, Hospital del Mar, Barcelona, Spain. ${ }^{8}$ Department of Molecular and Clinical Pharmacology, University of Liverpool, Liverpool, UK. ${ }^{9}$ Burns, Trauma and Critical Care Research Centre, The University of Queensland, Brisbane, Australia. ${ }^{10}$ Department of Intensive Care Medicine, Royal Brisbane and Women's Hospital, Brisbane, Australia. ${ }^{11}$ Pharmacy Department, Royal Brisbane and Women's Hospital, Brisbane, Australia.
}

Received: 25 January 2018 Accepted: 26 March 2018 Published online: 15 April 2018

\section{References}

1. Milner JJ, Beck MA. The impact of obesity on the immune response to infection. Proc Nutr Soc. 2012;71:298-306.

2. Knibbe CA, Brill MJ, van Rongen A, Diepstraten J, van der Graaf PH, Danhof M. Drug disposition in obesity: toward evidence-based dosing. Annu Rev Pharmacol Toxicol. 2015;55:149-67.

3. Jain R, Chung SM, Jain L, Khurana M, Lau SW, Lee JE, et al. Implications of obesity for drug therapy: limitations and challenges. Clin Pharmacol Ther. 2011;90:77-89.

4. Roberts JA, Lipman J. Pharmacokinetic issues for antibiotics in the critically ill patient. Crit Care Med. 2009;37:840-51.

5. Alobaid AS, Hites M, Lipman J, Taccone FS, Roberts JA. Effect of obesity on the pharmacokinetics of antimicrobials in critically ill patients: a structured review. Int J Antimicrob Agents. 2016;47:259-68.

6. Chandrasekar PH, Sobel JD. Micafungin: a new echinocandin. Clin Infect Dis. 2006:42:1171-8.

7. Pappas PG, Kauffman CA, Andes DR, Clancy CJ, Marr KA, Ostrosky-Zeichner $L$, et al. Executive summary: clinical practice guideline for the management of candidiasis: 2016 update by the Infectious Diseases Society of America. Clin Infect Dis. 2016;62:409-17.

8. Paiva JA, Pereira JM, Tabah A, Mikstacki A, de Carvalho FB, Koulenti D, et al. Characteristics and risk factors for 28-day mortality of hospital acquired fungemias in ICUs: data from the EUROBACT study. Crit Care. 2016;20:53.

9. Andes D, Ambrose PG, Hammel JP, Van Wart SA, lyer V, Reynolds DK, et al. Use of pharmacokinetic-pharmacodynamic analyses to optimize therapy with the systemic antifungal micafungin for invasive candidiasis or candidemia. Antimicrob Agents Chemother. 2011;55:2113-21.

10. Turnidge J, Paterson DL. Setting and revising antibacterial susceptibility breakpoints. Clin Microbiol Rev. 2007;20:391-408.

11. Maseda E, Grau S, Villagran MJ, Hernandez-Gancedo C, Lopez-Tofiño A, Roberts JA, et al. Micafungin pharmacokinetic/pharmacodynamic adequacy for the treatment of invasive candidiasis in critically ill patients on continuous venovenous haemofiltration. J Antimicrob Chemother. 2014;69:1624-32.

12. Le Gall JR, Lemeshow S, Saulnier F. A new simplified acute physiologic score (SAPS-II) based on a European/North-American multicenter study. JAMA. 1993;270:2957-63.

13. Vincent JL, Moreno R, Takala J, Willatts S, De Mendonça A, Bruining H, et al. The SOFA (Sepsis-related Organ Failure Assessment) score to describe organ dysfunction/failure. Intensive Care Med. 1996;22:707-10.

14. León C, Ruiz-Santana S, Saavedra P, Almirante B, Nolla-Salas J, Alvarez-Lerma $\mathrm{F}$, et al. A bedside scoring system ("Candida score") for early antifungal treatment in nonneutropenic critically ill patients with Candida colonization. Crit Care Med. 2006;34:730-7.

15. Alobaid AS, Wallis SC, Jarrett P, Starr T, Stuart J, Lassig-Smith M, et al. Population pharmacokinetics of piperacillin in nonobese, obese, and morbidly obese critically ill patients. Antimicrob Agents Chemother. 2017;61:e01276-316.

16. Food and Drug Administration. Guidance for industry: bioanalytical method validation. Rockville: U.S. Department of Health and Human Services, Food and Drug Administration, Center for Drug Evaluation and Research (CDER), Center for Veterinary Medicine (CVM); 2001.

17. Tatarinova T, Neely M, Bartroff J, van Guilder M, Yamada W, Bayard D, et al. Two general methods for population pharmacokinetic modelling: nonparametric adaptive grid and non-parametric Bayesian. J Pharmacokinet Pharmacodyn. 2013:40:189-99.

18. Neely MN, van Guilder MG, Yamada WM, Schumitzky A, Jelliffe RW. Accurate detection of outliers and subpopulations with Pmetrics, a nonparametric and parametric pharmacometric modeling and simulation package for $\mathrm{R}$. Ther Drug Monit. 2012;34:467-76.

19. Mentré F, Escolano S. Prediction discrepancies for the evaluation of nonlinear mixed-effects models. J Pharmacokinet Pharmacodyn. 2006;33:345-67.

20. Pfaller MA, Messer SA, Woosley LN, Jones RN, Castanheira M. Echinocandin and triazole antifungal susceptibility profiles for clinical opportunistic yeast and mold isolates collected from 2010 to 2011: application of new CLSI clinical breakpoints and epidemiological cutoff values for characterization of geographic and temporal trends of antifungal resistance. J Clin Microbiol. 2013;51:2571-81. 
21. Wasmann RE, Muilwijk EW, Burger DM, Verweij PE, Knibbe CA, Brüggemann RJ. Clinical pharmacokinetics and pharmacodynamics of micafungin. Clin Pharmacokinet. 2017; https://doi.org/10.1007/s40262-017-0578-5. [Epub ahead of print].

22. Jullien V, Azoulay E, Schwebel C, Le Saux T, Charles PE, Cornet M, et al. Population pharmacokinetics of micafungin in ICU patients with sepsis and mechanical ventilation. J Antimicrob Chemother. 2017;72:181-9.

23. Lempers VJ, Schouten JA, Hunfeld NG, Colbers A, van Leeuwen HJ, Burger $\mathrm{DM}$, et al. Altered micafungin pharmacokinetics in intensive care unit patients. Antimicrob Agents Chemother. 2015;59:4403-9.

24. Martial LC, Ter Heine R, Schouten JA, Hunfeld NG, van Leeuwen HJ, Verweij PE, et al. Population pharmacokinetic model and pharmacokinetic target attainment of micafungin in intensive care unit patients. Clin Pharmacokinet. 2017; https://doi.org/10.1007/s40262-017-0509-5. [Epub ahead of print].

25. Chang CC, Slavin MA, Chen SC. New developments and directions in the clinical application of the echinocandins. Arch Toxicol. 2017;91:1613-21.

26. Gumbo T, Hiemenz J, Ma L, Keirns JJ, Buell DN, Drusano GL. Population pharmacokinetics of micafungin in adult patients. Diagn Microbiol Infect Dis. 2008;60:329-31.

27. Hall RG, Swancutt MA, Gumbo T. Fractal geometry and the pharmacometrics of micafungin in overweight, obese, and extremely obese people. Antimicrob Agents Chemother. 2011;55:5107-12.

28. Pasipanodya JP, Hall RG 2nd, Gumbo T. In silico-derived bedside formula for individualized micafungin dosing for obese patients in the age of deterministic chaos. Clin Pharmacol Ther. 2015;97:292-7.

29. Andes D, Diekema DJ, Pfaller MA, Bohrmuller J, Marchillo K, Lepak A. In vivo comparison of the pharmacodynamic targets for echinocandin drugs against Candida species. Antimicrob Agents Chemother. 2010;54:2497-506.

30. Kuse ER, Chetchotisakd P, da Cunha CA, Ruhnke M, Barrios C, Raghunadharao D, et al. Micafungin versus liposomal amphotericin B for candidaemia and invasive candidosis: a phase III randomised double-blind trial. Lancet. 2007;369:1519-27.

31. Alobaid AS, Wallis SC, Jarrett P, Starr T, Stuart J, Lassig-Smith M, et al. Effect of obesity on the population pharmacokinetics of fluconazole in critically ill patients. Antimicrob Agents Chemother. 2016;60:6550-7.

32. Lempers VJ, van Rongen $A$, van Dongen EP, van Ramshorst $B$, Burger DM, Aarnoutse RE, et al. Does weight impact anidulafungin pharmacokinetics? Clin Pharmacokinet. 2016;55:1289-94.

33. Yang $Q$, Wang $T$, Xie J, Wang Y, Zheng X, Chen $L$, et al. Pharmacokinetic/ pharmacodynamic adequacy of echinocandins against Candida spp. in intensive care unit patients and general patient populations. Int J Antimicrob Agents. 2016;47:397-402.

34. Zomp A, Bookstaver PB, Ahmed Y, Turner JE, King C. Micafungin therapy in a critically ill, morbidly obese patient. J Antimicrob Chemother. 2011;66:2678-80.

35. Flegal KM, Kruszon-Moran D, Carroll MD, Fryar CD, Ogden CL. Trends in obesity among adults in the United States, 2005 to 2014. JAMA. 2016; 315:2284-91.

36. Sirohi B, Powles RL, Chopra R, Russell N, Byrne JL, Prentice HG, et al. A study to determine the safety profile and maximum tolerated dose of micafungin (FK463) in patients undergoing haematopoietic stem cell transplantation. Bone Marrow Transplant. 2006;38:47-51.

37. Pappas PG, Rotstein CM, Betts RF, Nucci M, Talwar D, De Waele JJ, et al. Micafungin versus caspofungin for treatment of candidemia and other forms of invasive candidiasis. Clin Infect Dis. 2007:45:883-93.

38. Goto N, Hara T, Tsurumi H, Ogawa K, Kitagawa J, Kanemura N, et al. Efficacy and safety of micafungin for treating febrile neutropenia in hematological malignancies. Am J Hematol. 2010;85:872-6.

39. Nguyen TH, Hoppe-Tichy T, Geiss HK, Rastall AC, Swoboda S, Schmidt J, et al. Factors influencing caspofungin plasma concentrations in patients of a surgical intensive care unit. J Antimicrob Chemother. 2007;60:100-6.

40. Hall RG, Swancutt MA, Meek C, Leff R, Gumbo T. Weight drives caspofungin pharmacokinetic variability in overweight and obese people: fractal power signatures beyond two-thirds or three-fourths. Antimicrob Agents Chemother. 2013;57:2259-64

41. Ferriols-Lisart R, Aguilar G, Pérez-Pitarch A, Puig J, Ezquer-Garín C, Alós M. Plasma concentrations of caspofungin in a critically ill patient with morbid obesity. Crit Care. 2017;21:200.

42. Liu P, Ruhnke M, Meersseman W, Paiva JA, Kantecki M, Damle B. Pharmacokinetics of anidulafungin in critically ill patients with candidemia/ invasive candidiasis. Antimicrob Agents Chemother. 2013;57:1672-6.

\section{Submit your next manuscript to BioMed Central and we will help you at every step:}

- We accept pre-submission inquiries

- Our selector tool helps you to find the most relevant journal

- We provide round the clock customer support

- Convenient online submission

- Thorough peer review

- Inclusion in PubMed and all major indexing services

- Maximum visibility for your research

Submit your manuscript at www.biomedcentral.com/submit
Biomed Central 